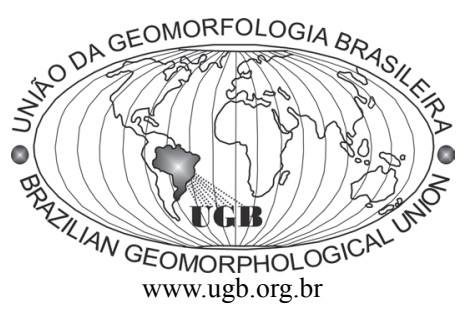

Revista Brasileira de Geomorfologia - v. 12, nº 3 (2011)

\title{
CARTOGRAFIA GEOMORFOLÓGICA DETALHADA: A REPRESENTAÇÃO GRÁFICA DO RELEVO ENTRE 1950-1970
}

\author{
Lylian Coltrinari \\ Programa de Pós-graduação em Geografia Física FFLCH/USP, C. P. 72042 - \\ CEP 05.508-900 - São Paulo/SP - e-mail: lylian@usp.br
}

\begin{abstract}
Resumo
Sistemas de cartografia geomorfológica propostos por países europeus, entre eles Polônia, França e Rússia, datam dos anos 1950; os congressos da UGI balizaram a evolução da cartografia desde 1956 quando cartas geomorfológicas detalhadas foram apresentadas no Congresso Internacional de Geografia do Rio de Janeiro. Em 1960, a UGI criou, na Comissão de Geomorfologia Aplicada, a Subcomissão de Cartografia Geomorfológica que estabeleceu regras para execução das cartas e determinou a prática de levantamentos específicos para a pesquisa geomorfológica. Adotaram-se princípios uniformes para permitir comparações entre cartas e subsidiar o planejamento econômico com representações corretas do relevo. Em 1962, a Conferência Internacional da UGI na Polônia analisou mapas geomorfológicos de 14 países, mas a disparidade de conteúdos e formas de representação prejudicou comparações entre eles. Para incentivar a construção de mapas compatíveis se recomendou a realização de mapas baseados em trabalho de campo complementado com fotos aéreas, plotados em cartas topográficas detalhadas e produzidos em escalas de 1:10.000 - 1:100.000. A representação completa do relevo do ponto de vista da dinâmica requeria a inclusão de dados morfográficos, morfológicos, morfogenéticos e morfocronológicos e a identificação das feições por meio de signos multicoloridos. A composição da lista de formas e a escolha dos signos da legenda tiveram como base legendas existentes e/ou dados de mapas geomorfológicos de áreas com históricos geológico-ambientais diversos; a legenda deveria ser continuamente atualizada e complementada com dados de regiões diversas daquelas onde se originaram os sistemas existentes. Em 1972, Demek editou o Manual de Cartografia Geomorfológica Detalhada, que sistematiza resultados de propostas discutidas pela Subcomissão no Congresso da UGI em Nova Delhi (1968).
\end{abstract}

Palavras-chave: Princípios da cartografia geomorfológica; legenda e carta geomorfológica detalhada; UGI.

\begin{abstract}
In the 1950's geomorphological mapping systems were proposed in diverse European countries, notably Poland, France and Russia; later evolution can traced back to 1956 when detailed geomorphological maps were presented in the IGU International Congress (Rio de Janeiro). In 1960, was formed a sub-commission on geomorphological mapping within the Commission on Applied Geomorphology; principles for execution of geomorphological mapping and the adoption of specific survey for geomophological research were proposed. Uniform ideas and principles for map construction should allow comparisons among geomorphological maps and supply national economies with detailed maps and appropriate representation of landforms. In 1962, an international conference of the UGI in Poland reviewed geomorphological maps performed in 14 countries but comparisons were difficult due to disparities in content and manners of representation. To emphasize the relevance of comparable maps the conference recommended that maps should be based on field data supplemented by aerial photographs, plotted on detailed topographic maps and produced on scales $1: 10,000-1: 100,000$. Complete representation of relief from the standpoint of dynamics required the inclusion of morphometric, morphographic, morphogenetical and morphochronological data and features identified by multicoloured signs. The sub-commission was directly responsible for the unified legend's list of landforms and choice of signs, based upon existing keys and/or data from earlier geomophological maps representing diverse geological and climatic environments; it should be permanently completed. In 1972, J. Demek edited the Manual of Detailed Geomorphological Mapping that systematizes results of former proposals discussed by the sub-commission in the UGI 1968 congress in New Delhi.
\end{abstract}

Keywords: Principles of map construction; detailed geomorphological map and legend; UGI. 
(...) O elemento essencial de uma carta geomorfológica é sua legenda. É ela que requer rigor intelectual; é também nela que a falta de rigor é facilmente percebida. A legenda do mapa deve ser organizada de tal forma que a descrição e a interpretação estejam separadas; em outras palavras, deveria ser possível a quem estudasse o mapa chegar a uma conclusão diferente daquela do autor. Se os dados não podem ser reinterpretados, o mapa não passa de uma simples ilustração do autor (...).

(TRICART, 1959; ST-ONGE, 1964, in ST-ONGE, 1981)

\section{Introdução}

A geomorfologia estuda as formas da superfície terrestre, sua distribuição e suas relações mútuas, sua origem e sua evolução passada e atual. Estudos geomorfológicos não se preocupam especificamente com a forma do planeta, mas com aquelas que identificamos em sua superfície, seja esta subaérea ou submarina, das placas litosféricas às crateras modeladas pelas gotas de chuva, indo daquelas que permanecem por milhões de anos às que duram menos de um segundo.

É provável que a extrema variedade espaço-temporal das feições da superfície e do significado histórico-genético dos conjuntos de formas e materiais (DYLIK, 1968) tenham despertado nos praticantes da geomorfologia a preocupação com a descrição e a classificação de seus objetos de estudo. Esta necessidade os levou a emprestar da geografia procedimentos descritivos e classificatórios por ela desenvolvidos, em particular os relacionados com os aspectos morfométricos e morfológicos. A necessidade de representação desses fatos conduziu, mais tarde, ao desenvolvimento da cartografia temática específica onde, aos elementos descritivos já citados, foram incorporadas informações genéticas e cronológicas.

\section{Objetivos}

Este texto apresenta um histórico da fase inicial da cartografia geomorfológica detalhada e sua contribuição ao conhecimento do relevo terrestre mediante a proposição de bases teóricas e metodológicas específicas para levantamentos de campo e construção de documentos para pesquisas básicas e aplicadas. Destaca o papel da União Geográfica Internacional (UGI) como instituição que apoiou, por volta dos anos 1950 , as tentativas iniciais de sistematização dos conhecimentos adquiridos nas pesquisas aplicadas ao planejamento em sistemas de cartografia básica organizados em legendas baseadas em critérios e métodos geomorfológicos. A UGI acolheu e estimulou sucessivos encontros de especialistas na procura de um sistema internacional único de representação do relevo, que culminou então com a publicação do Manual de Cartografia Geomorfológica Detalhada no início dos anos 1970.

\section{Justificativa}

Numa época em que o aumento das pressões sobre a biosfera demanda ações rápidas contra a degradação ambiental e os efeitos das ações antropogênicas é preciso formular respostas pró-ativas. Os mapas geomorfológicos estão entre os produtos mais importantes das pesquisas geomorfológicas em qualquer escala e área e são úteis para os especialistas em pesquisas de paisagem, planejamento rural e urbano, ciência do solo, agrônomos e profissionais afins. Contudo, o potencial das contribuições básicas e aplicadas da cartografia geomorfológica é pouco conhecido e as cartas geomorfológicas perdem espaço como instrumento de representação da evolução e estado do relevo perante meios e produtos digitais de pesquisa. $\mathrm{O}$ desconhecimento da história de sua evolução e a dos conflitos teóricos e práticos que entravam a pesquisa e a produção de cartas impede o conhecimento e compreensão de sua relevância na pesquisa pura e aplicada, tanto entre profissionais e pesquisadores das Ciências da Terra quanto de outras comunidades científicas (PARON \& SMITH, 2009).

Quanto à perda de espaço e visibilidade dos documentos geomorfológicos clássicos ou pré-digitais - produzidos manualmente e/ou por meios analógicos pelos participantes do processo inteiro, do campo ao desenho das pranchas para montagem da carta - explica-se, em parte, pelo tempo transcorrido entre o início da pesquisa e a aprovação da primeira prancha impressa pelo coordenador do projeto e a publicação.

\section{Cartografia geomorfológica: os primórdios}

Há séculos, os mapas topográficos representam as formas de relevo mediante técnicas diversas - hachuras desde o século XVIII, curvas de nível desde o XIX, que permitem diferenciar atributos morfológicos e morfográficos do relevo, mas não informam sobre origem, processos de evolução e idade das formas cartografadas (KLIMASZEWSKI, 1982).

Os princípios básicos dos mapas geomorfológicos foram propostos por PASSARGE em artigo publicado em 1912 e desenvolvidos no Morphologischer Atlas (PASSARGE, 1914, 1920, in KLIMASZEWSKI, 1988). A publicação incluía, em escala 1:50.000, oito mapas: 1) topo-orográfico com vegetação, 2$)$ de declividade das vertentes $\left(0-5^{\circ}, 5-10^{\circ}\right.$, $\left.10^{\circ}-20^{\circ}, 20^{\circ}-35^{\circ},>35^{\circ}\right), 3$ ) das formas de vales, 4) geológico-estratigráfico, 5) de resistência física, 6) de resistência química, 7) petrográfico e 8) de desenvolvimento do relevo, os elementos desse relevo e seu evolução, a estrutura do substrato e sua susceptibilidade ao intemperismo. Na mesma época, GEHNE (1912, in KLIMASZEWSKI, 1988) publicara uma carta que incluía, de acordo com os princípios do autor, informações sobre morfografia, estrutura, morfologia e origem do relevo. 
As ideias de Passarge tiveram pouca repercussão entre os geógrafos da época, que continuaram limitandose a descrições literárias de formas e tipos de relevo. As pesquisas focalizavam as formas mais espetaculares, como escorregamentos e quedas de rocha, mas as vertentes onde esses processos aconteciam não eram estudadas como um todo. De acordo com Klimaszewski (1982), esses estudos não ofereciam suporte para o conhecimento da evolução do relevo ou para uso prático, já que não procuravam correlações entre formas isoladas ou conjuntos específicos.

Nas décadas seguintes, mapas morfológicos e legendas para mapas geomorfológicos em escalas de 1:50.000 a 1:500.000 foram produzidos na Europa central e oriental mas a cartografia geomorfológica continuou a ser menosprezada. Os mapas de Passarge permaneceram como exemplo único de seu tipo até depois da Segunda Grande Guerra (19391945) quando planejadores, engenheiros, agrônomos e outros especialistas requisitavam documentos mais precisos e úteis do que "discussões eruditas em relatórios científicos" (St. Onge, 1968, p. 389).

Enquanto isso, nos Estados Unidos, o estudo do relevo era dominado por uma fisiografia descritiva (HAYDEN, 1989) durante o século XIX e primeiras décadas do século XX e a paisagem era apresentada em textos onde blocos-diagrama artísticos ilustravam as conclusões do autor: os estudos não incluíam todas as formas de relevo, as tentativas de correlação eram escassas e não havia sistemas de classificação detalhada (KLIMASZEWSKI, 1988). Na França, cartas geomorfológicas de pequena e média escala eram resultado de "traduções" gráficas de relatórios, teses e monografias já que a escassez de recursos para a pesquisa limitava os levantamentos de campo detalhados (TRICART, 1963). Da primeira edição do Atlas de France (1951-1958) consta uma carta 1:1.000.000 da autoria de Emmanuel de Martonne e, em 1956, Cholley publicara a carta-síntese da Bacia de Paris (1:400.000) (JOLY, 1973).

Finalizada a Segunda Grande Guerra (1939-1945), com o auxílio das fotografias aéreas foram desenvolvidos estudos detalhados do relevo e do modelado e das relações entre embasamento, clima e gênese das formas observadas e registradas em mapas topográficos em escalas 1:50.000 ou maiores. A compilação dos produtos dessa cartografia foi iniciada, entre outros, por Boesch (1945), Klimaszewski (1950, 1953) e Tricart (1954).

A partir dos anos 1950, a cartografia geomorfológica, adotada como método para a pesquisa básica de geomorfologia sustentou o desenvolvimento da disciplina enquanto corpo teórico e conhecimento aplicado a questões práticas (GELLERT, 1972). Nessa década, geógrafos franceses e poloneses publicaram as primeiras cartas detalhadas em escalas diversas com base em levantamentos de campo. Equipes coordenadas por J. Tricart, F. Joly, A. Journaux e
I. Dewolf realizaram levantamentos na França Continental, América Latina, Delta do Senegal e África do Norte (JOLY, 1973) enquanto na Polônia M. Klimaszewski coordenava a execução do projeto do mapa geomorfológico detalhado pelos pesquisadores dos institutos de geografia da Academia de Ciências e das universidades (KLIMASZEWSKI, 1963a). Resultados dessas pesquisas foram apresentados na Conferência Internacional da Polônia em 1962.

\section{A UGI e o desenvolvimento da cartografia geomor- fológica}

Em 1956, durante o $18^{\circ}$ Congresso Internacional da União Geográfica Internacional (UGI), no Rio de Janeiro, foi reconhecida a importância das cartas geomorfológicas detalhadas desde então incluídas entre as tarefas importantes da Comissão de Geomorfologia Aplicada. Nesse evento foram também apresentadas duas conferências sobre concepções diferentes de cartas geomorfológicas detalhadas: a de A. Annaheim (Cartes géomorphologiques) e de M. Klimaszewski (The principles of geomorphological mapping in Poland).

No $19^{\circ}$ Congresso da UGI (Estocolmo, 1960), as comunicações sobre cartografia geomorfológica mostraram diversidade de conteúdo e formas de representação entre os sistemas desenvolvidos - entre outros países - pela Suíça, França, ex-URSS, Japão, Polônia e Portugal, resultantes de concepções diversas e princípios independentes para construção das cartas geomorfológicas. A necessidade de propor e discutir princípios gerais unificadores para a realização de mapas comparáveis, ainda que construídos em ambientes geológicos e climáticos distintos, resultou na criação - no âmbito da Comissão de Geomorfologia Aplicada - de uma Subcomissão de Cartografia Geomorfológica, presidida por Klimaszewski, cujos objetivos seriam:

- introduzir e desenvolver a metodologia do mapeamento geomorfológico;

- adotar um sistema e princípios uniformes de cartografia para assegurar sua comparabilidade;

- oferecer, mediante os mapas geomorfológicos, subsídios para o conhecimento do ambiente geográfico e seu uso racional (KLIMASZEWSKI, 1982, p. 266).

Para discutir e levar à prática essas propostas foram realizadas sessões anuais na Polônia (1962), França (1962, 1963), Grã Bretanha (1964) Tchecoslováquia (1965) Bélgica (1966) e ex-URSS (1967) que contaram com o apoio da UGI nos esforços de cooperação entre pesquisadores da Europa oriental e central, da França e do Canadá para desenvolvimento da cartografia geomorfológica detalhada (FAIRBRIDGE, 1968). 


\section{A Conferência Internacional da Polônia}

\begin{abstract}
(...) O objetivo da geomorfologia é examinar o relevo da superfície terrestre. O relevo (...) é elemento muito importante do ambiente geográfico. O conhecimento desse ambiente, de seus elementos especificos - isto é, também do relevo - é necessário não apenas para o desenvolvimento da ciencia mas também para o controle racional e o uso que o homem faz desse ambiente. O objeto (sic) da geomorfologia é duplo: 1) o exame do relevo para ter ideia de seu desenvolvimento e das regras desse desenvolvimento; 2) o exame do relevo para facilitar o melhor controle e uso que o homem faz desse ambiente. (...)
\end{abstract}

M. Klimaszewski, Problems of geomorphological mapping (1963)

Entre 3 e 12 de maio de 1962, aconteceu em Cracóvia a Conferência da Subcomissão de Cartografia Geomorfológica, convidada pela Comissão de Geomorfologia Aplicada (UGI) e pelo Instituto de Geografia da Academia Polonesa de Ciências. O país sede foi escolhido em reconhecimento à qualidade e ao desenvolvimento alcançado pela cartografia geomorfológica no país, já que, em 1950, os geógrafos físicos haviam iniciado levantamento baseado na carta geomorfológica detalhada e mapearam entre 1950 e 1955 uma área de $50.000 \mathrm{~km}^{2}$ (KLIMASZEWSKI, 1959).

Entre os objetivos propostos para discussão na Conferência foram sugeridos a avaliação das "cartas geomorfológicas detalhadas" realizadas até então em diversos países e a discussão e proposta de princípios para a construção das cartas geomorfológicas detalhadas que garantissem a comparação entre mapas realizados por diversos autores em países diferentes. Para tanto seria preciso que a escala e a abrangência do conteúdo dessa carta detalhada fossem especificados, assim como o conteúdo da legenda uniforme - ou os princípios de sua construção - , para assegurar a legibilidade e a comparabilidade entre cartas de áreas diversas por diferentes autores.

Os propósitos inclusos no programa da Comissão unificação dos conteúdos e dos meios de representação dos mapas geomorfológicos detalhados - seriam confrontados com a realidade expressa nas cartas das áreas visitadas nas excursões e nos mapas de 14 países exibidos durante a Conferência. Entretanto, o caminho possível para a aplicação universal e uniforme dos princípios de uma legenda única para mapear áreas com histórias geológicas e climáticas diversas aberto pela resolução era - e continua sendo - restrito.

Como amostras dessa diversidade e das soluções cartográficas apresentadas na conferência foram escolhidas cartas realizadas por autores poloneses na região de Cracóvia e por pesquisadores franceses no Delta do Rio Senegal (África).

\section{A cartografia geomorfológica detalhada na Po- lônia}

O projeto de construção da carta geomorfológica na escala de 1:50.000 da Polônia teve seu início em 1946 com o objetivo de conhecer com precisão os elementos do ambiente geográfico e os aspectos qualitativos e quantitativos do relevo mediante a análise de todas as formas de uma área específica. As formas eram plotadas num mapa topográfico, aplicando o método do levantamento geomorfológico, isto é, localizando todas as formas identificadas no trabalho de campo - previamente descritas, medidas e classificadas genética e cronologicamente por meio de signos e cores.

O mapa geomorfológico polonês informava assim a aparência (morfografia), as dimensões (morfometria), a origem (morfogênese) e a idade (morfocronologia) das formas identificadas, permitindo, a princípio, inferir o caráter da evolução do relevo, conquanto se considerassem a estrutura geológica e as mudanças do ambiente geográfico durante o desenvolvimento desse relevo. O resultado foi o 'Mapa geomorfológico da Polônia' (1:25.000 no campo, 1:50.000 na versão impressa) inteiramente completado no campo (KLIMASZEWSKI, 1963c; 1982).

\section{Avaliação do relevo para planejamento territorial - Região de Cracóvia (1:25.000) (POKORNY \& TYCZYNSKA, 1963).}

Durante as excursões programadas pela Conferência da UGI na região de Cracóvia e zona periurbana foram apresentados 20 mapas geomorfológicos e de avaliação do relevo para fins econômicos $(1: 25.000)$ realizados entre 1957 e 1962 . Como subsídio ao planejamento urbano de uma área aproximada de $2.000 \mathrm{~km}^{2}$ foram produzidos um mapa geomorfológico (1:25.000) (Figura 1A), um mapa geomorfológico de avaliação (1:25.000) (Figura 1B) e um texto explicativo, documentos baseados em KLIMASZEWSKI (1959) e nos resultados do trabalho de campo. 
As formas foram classificadas de acordo com a aptidão para:

1- construção de edifícios;

2- construção de estradas;

3 - uso agrícola.

O mapa das formas avaliadas foi desenhado em papel transparente a quatro cores que, quando superposto ao mapa geomorfológico, permitia o reconhecimento de cada classe específica de relevo e da porcentagem de território ocupada por ela em cada unidade administrativa. $\mathrm{O}$ texto explicativo anexo a cada folha detalhava 1 - localização da área e síntese de resultados anteriores; 2 - descrição das principais informações geológicas e geomorfológicas e divisão em unidades geomorfológicas; 3 - inventário das formas, sua distribuição e características detalhadas; 4 - características morfográficas, morfométricas, morfocronológicas e morfogenéticas do relevo em cada unidade geomorfológica, e 5 - avaliação do relevo para fins de planejamento em cada unidade administrativa (cidade, vila, etc.) (POKORNY \& TYCZYNSKA, 1963).
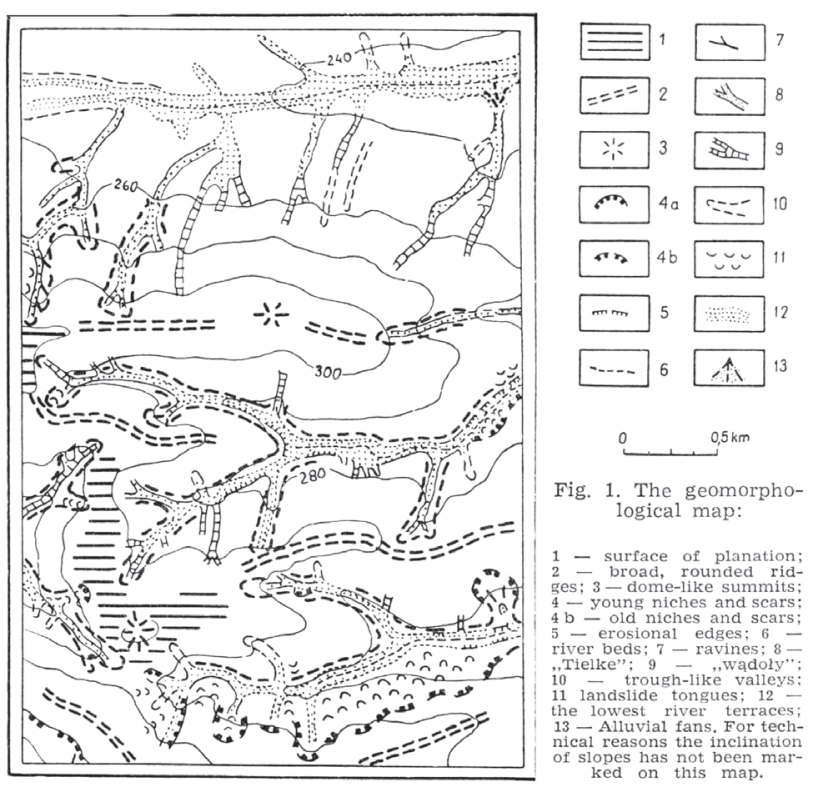

Figura 1A - Mapa geomorfológico

1: superficie de aplainamento; 2: divisores largos convexos; 3 : topos em forma de domo; $4 a$ : nichos e cicatrizes recentes; $4 b$ : nichos e cicatrizes antigos; 5: bordas erosivas; 6: leitos fluviais; 7: ravinas; 8: "Tielke"; 9: "wadoly"; 10: vales encaixados; 11: língua de escorregamento; 12: terraços baixos; 13: leques aluviais. Declividade das vertentes não indicadas no mapa.

Adapt. de Tokorny \& Tyczynska (1963). Trad./org.: Coltrinari (2009).

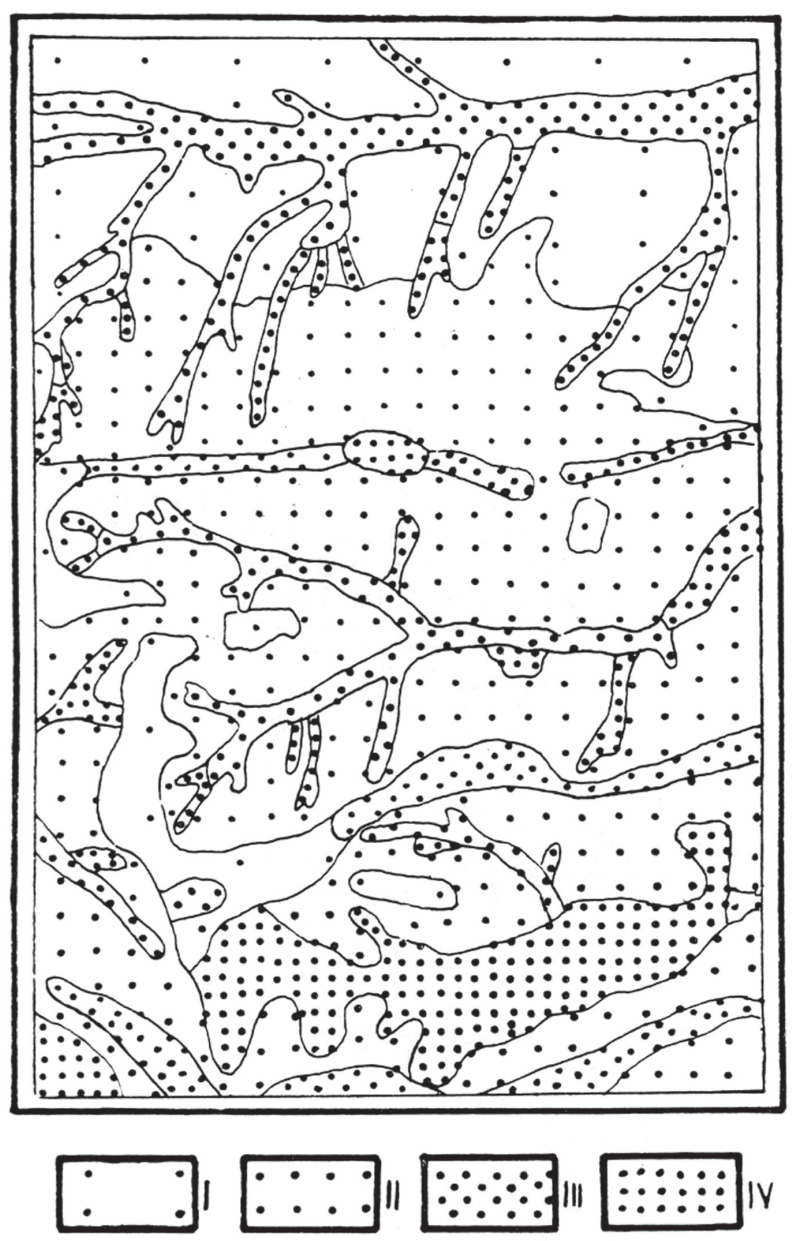

Fig. 2. The geomorphological evaluation map:

I - forms generally suitable for house building, road construction and cultivation; II - forms making house building difficult; III forms making house building and road construction in the direction of the maximum inclination of slopes difficult; IV - forms making house building, road construction and cultivation difficult.

Figura 1B - Mapa geomorfológico de avaliação

I: relevo geralmente adequado para edifícios, estradas e uso agricola;

II: inadequado para edificios;

III:- inadequado para edifícios e vias de circulação no sentido da declividade;

IV: inadequado para todo tipo de uso. Adapt. de Tokorny \& Tyczynska (1963) Trad./org.: Coltrinari (2009).

\section{A contribuição francesa à cartografia geomorfoló- gica detalhada}

O desenvolvimento da cartografia geomorfológica detalhada na França teve seu início nos anos 1950 com a publicação das Cartas do Delta do Senegal, da França Continental e da América do Sul levantadas pela equipe do Centro de Geografia Aplicada (C.G.A.) de 
Estrasburgo coordenada por J. Tricart, as cartas geomorfológicas da África do Norte e da Franca de F. Joly e A. André e as cartas de formações superficiais de A. Journaux e Y. Dewolf. Os resultados das pesquisas, a discussão de legendas adequadas a diferentes contextos físicos e regiões naturais e a definição de escalas pertinentes à representação geomorfológica de fatos de relevo foram apresentados e discutidos na Subcomissão de Cartografia Geomorfológica Detalhada da Comissão de Geomorfologia Aplicada da UGI. Anos depois, o interesse dos pesquisadores franceses na definição de uma metodologia para a cartografia geomorfológica deu origem à Recherche Cooperative sur Programme $n^{\circ} .77$ (R.C.P. 77) do Centre National de la Recherche Scientifique (C.N.R.S.) que aglutinou especialistas em cartografia geomorfológica e estabeleceu uma legenda para a carta geomorfológica detalhada em 1:50.000. Os resultados das pesquisas desenvolvidas na França e no exterior foram reunidos no volume Cartographie Géomorphologique, travaux de la R.C.P. 77, publicado pelo C.N.R.S. em 1971 (JOLY, 1973).

Uma versão em espanhol - Leyenda para el mapa geomorfológico de Francia (1:50.000), traduzida e adaptada por D. Serrat, L. Solé Sabaris e J. Calvet Porta, foi publicada em 1976 pelo Conselho Superior de Pesquisa Científica (C.S.I.C.) da Espanha (SERRAT, 1976).

\section{Carta geomorfológica do Delta do Senegal - Folha Rosso (1:50 000) (TRICART, 1959)}

Foi a primeira tentativa de cartografia geomorfológica aplicada realizada pela França e o ponto de partida das atividades do Centro de Geografia Aplicada (C.G.A.) de Estrasburgo no Baixo Vale e no Delta do Rio Senegal. As cartas tinham finalidade prática - planejamento agrícola, irrigação e melhora da navegação, entre outras - e, por representarem áreas específicas, os levantamentos foram descontínuos, assim como os mapas que resultaram deles (MICHEL, 1963). Além de documentos básicos para a pesquisa geomorfológica aplicada ao planejamento agrícola e urbano na Bacia do Senegal, as cartas revelaram a importância da cartografia geomorfológica para o desenvolvimento científico da disciplina (TRICART, 1959).

Dada a complexidade da área e a necessidade de reproduzir elementos diversos da paisagem, tanto isolados quanto agrupados, as soluções resultaram do trabalho conjunto de Sylvie Rimbert, - cartógrafa do C.G.A., e
J. Tricart e da troca de experiências destes com M. Klimaszewski. O sistema cartográfico escolhido combinava signos diversos e cores sobre a base topográfica; as cores identificavam a idade das formas e eram superpostas aos símbolos. Para representação do relevo do baixo vale e do delta, considerados como de idade quaternária, foram escolhidas cores na série do amarelo, o laranja, o vermelho e o vermelho escuro, onde as tintas progressivamente mais escuras correspondiam às idades mais antigas. As ações antrópicas foram representadas por elementos/ traços na cor verde que atravessam as séries quaternárias enquanto a topografia, a natureza das formas e a litologia foram representadas por símbolos.

A distinção entre formações coerentes e móveis foi estabelecida por meio de hachuras e de símbolos pontuais conforme a granulometria, respectivamente; no caso, a dimensão dos grãos é representada por meio do tamanho do símbolo respectivo (grande para as areias, umas duas vezes menor para argila e silte). Para o uso da terra importava a identificação dos materiais nas bacias de decantação do delta já que, nas partes altas, os sedimentos areno-siltosos não muito permeáveis serviam para cultivos enquanto as acumulações argilosas das partes baixas impediam a penetração das raízes até as camadas arenosas subpostas, sendo úteis só para o pastoreio de bovinos. De acordo com Tricart (1959), por mostrar corretamente as características do meio geomorfológico, a carta oferecia dados básicos para a organização do espaço, além de subsídios para a cartografia dos solos e da vegetação.

\section{Resoluções adotadas pela Conferência}

Após análise das cartas apresentadas e a constatação de divergências entre os respectivos conteúdos e metodologias, a Subcomissão de Cartografia Geomorfológica definiu diretrizes para a produção futura desses documentos; entre outras:

- a pesquisa de campo com apoio de fotos aéreas e registro em cartas topográficas como base obrigatória da construção das cartas geomorfológicas;

- a realização dos mapas detalhados em escalas entre 1:10.000 e 1:100.000 para permitir a representação precisa do relevo e a localização das feições, conforme a escala;

- a representação do relevo inclui todos os atributos do relevo - morfometria, morfografia, morfogênese, morfodinâmica e morfocronologia para que o passado, o presente e o futuro de seu desenvolvimento pudessem figurar. 


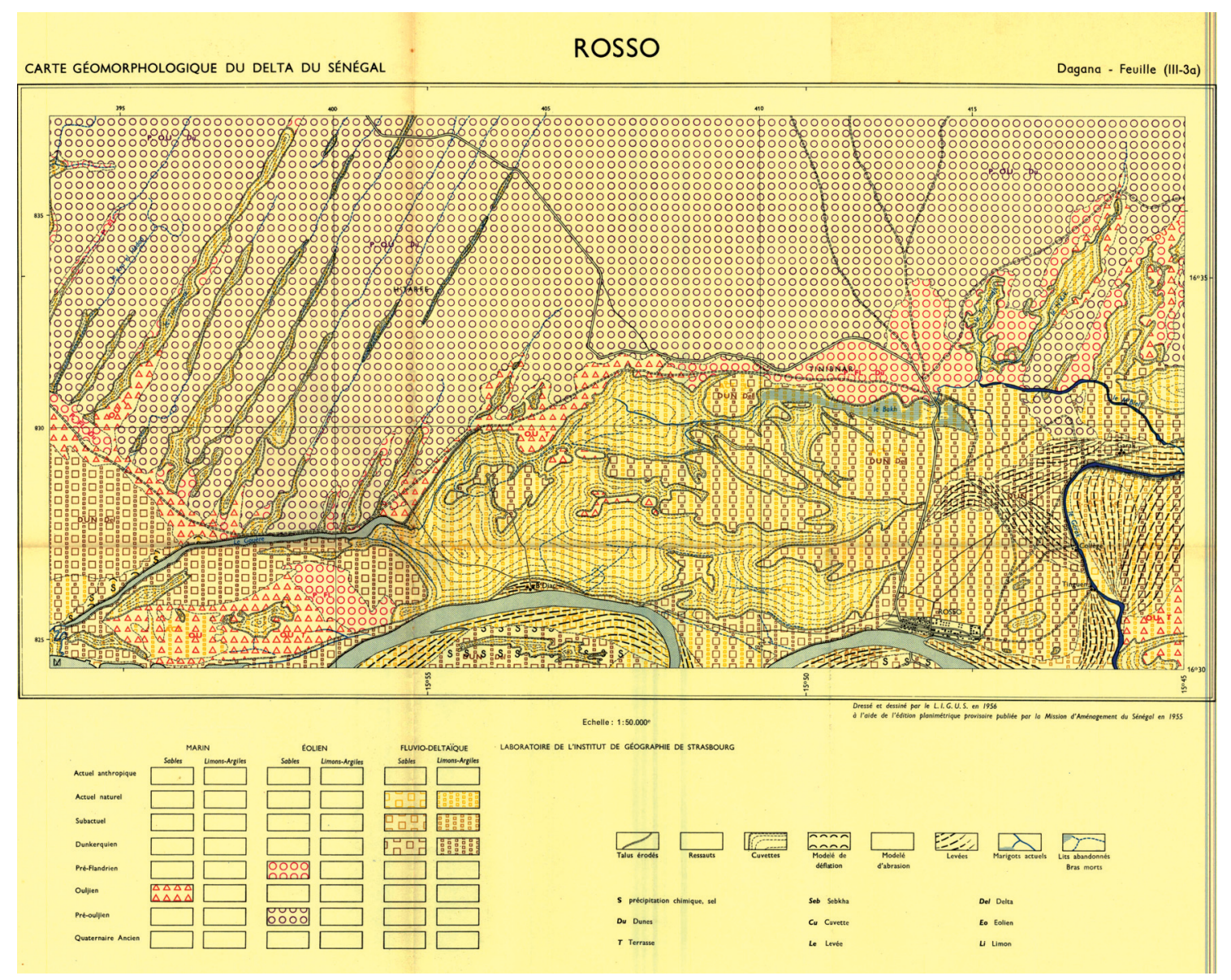

Figura 2 - Carta geomorfológica do Delta do Senegal - Rosso - Dagana Feuille (III-3a)

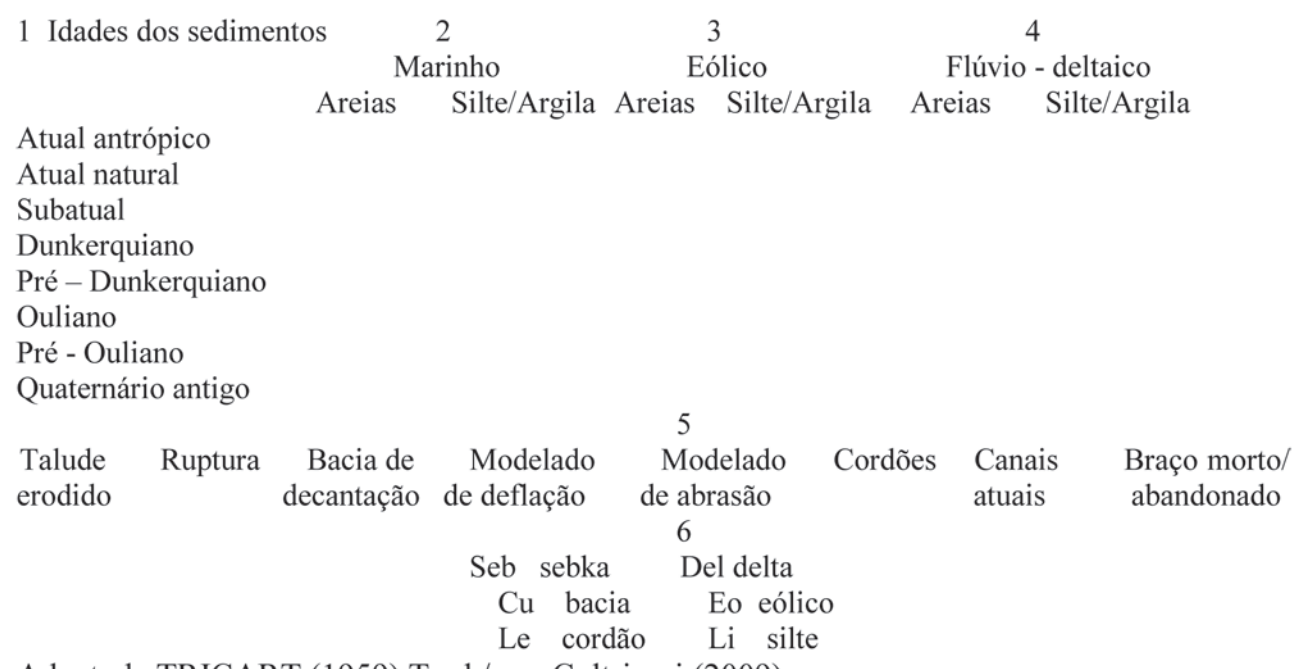

Adapt. de TRICART (1959) Trad./org. Coltrinari (2009) 
Recomendou-se também o uso de cores e símbolos como meios de informação, o uso de datações para estabelecimento da cronologia do desenvolvimento das formas, a inclusão da litologia com signos diferenciados e a atualização permanente da lista de formas classificadas segundo a ordem cronológico-genética (grifo da autora) (KLIMASZEWSKI \& TRICART, 1963). Com a anuência dos participantes de regiões com estruturas geológicas e climas diferentes [daqueles incluídos/considerados na construção] da Lista de relevo e signos utilizados na carta geomorfológica detalhada (KLIMASZEWSKI, 1963, p. 139-177), a proposta foi aceita.

As discussões sobre as resoluções adotadas e os princípios propostos em Cracóvia tiveram continuidade nas reuniões da Subcomissão de Cartografia Geomorfológica Detalhada na França (1962 e 1963), Grã Bretanha (1964), exChecoslováquia (1965), Bélgica (1966) e ex-URSS (1967). A colaboração e a troca de experiências entre geomorfólogos de diferentes origens e práticas de pesquisa em contextos diversos levaram à tomada de decisões como a de eliminar os mapas puramente morfológicos, morfométricos, morfografo/ morfométricos, morfométricos e estritamente morfogenéticos, do conjunto dos mapas geomorfológicos stricto sensu (KLIMASZEWSKI, 1982).

Foram também possíveis acordos entre os representantes de duas tendências diferentes na construção de mapas geomorfológicos detalhados. A produção de mapas estruturais - geomorfológicos, sustentada por geomorfólogos da França, ex-Checoslováquia e Hungria, defendia a continuidade das ideias de E. de Martonne materializadas na carta 1:1.000.000 no já mencionado Atlas de France (JOLY, 1973). O binômio litologia-estrutura é o elemento básico dessa cartografia, representado por manchas de cores diferentes sobre as quais são representadas as formas de relevo com idades, origens e tamanhos definidos e identificados por símbolos coloridos. Esses mapas informam sobre as relações entre as formas e a composição e estrutura do substrato, mas não são úteis para a reconstrução do desenvolvimento do relevo. Para os geomorfólogos poloneses, romenos e alemães, as formas são o elemento básico; portanto, o elemento de maior importância de seus mapas é o relevo, com dimensões, origens e idades definidas, e não a estrutura. De acordo com Klimaszewski (1988), esses mapas oferecem informações corretas sobre o caráter do relevo e possibilitam a reconstrução da evolução geomorfológica, não informando, entretanto, sobre as relações entre estrutura geológica e formas do relevo, que poderiam ser estabelecidas pela comparação entre mapas geomorfológicos e geológicos da mesma área.

O trabalho conjunto dos representantes dessas tendências resultou na redução do conteúdo geológico nos mapas geomorfológicos e na inclusão de dados estruturais-litológicos no caso de relevos estruturais, tectônicos e de acumulação. Também houve acordo sobre a abrangência do conteúdo, os princípios da cartografia e a elaboração das cartas geomorfológicas detalhadas segundo a legenda aprovada em Cracóvia e reuniões posteriores. Por conta desse consenso melhoraram as possibilidades de comparação quanto à abrangência do conteúdo (grifo da autora), mas as legendas dos mapas e os símbolos plotados nas cartas, que representavam as formas na localização correta, não eram compatíveis e, nesse sentido, as cartas não eram comparáveis. Para Klimaszewski (1982), os pesquisadores concordavam com a existência de mapas comparáveis e uma legenda única, mas relutavam em descartar os símbolos criados por eles, em geral empregados em pesquisas locais e áreas restritas.

Foi decidida então a criação de mais uma legenda uniforme para a qual seriam escolhidos cores e símbolos para diversas formas de dimensões, origens e idades diferentes no mundo inteiro. Foi escolhido um grupo de trabalho específico para produzir um mapa com escala entre 1:25.000 - 1:50.000, que fosse claro para os usuários, permitisse a reconstrução da evolução do relevo e a avaliação da natureza e magnitude dos processos atuais e seu comportamento futuro. Deveria também informar sobre a distribuição e correlação de formas com aspecto, tamanho, origem e idade específicos e incluir dados morfográficos, morfométricos, morfogenéticos e morfocronológicos (KLIMASZEWSKI, 1988). O mapa submetido ao Congresso da UGI de Nova Dehli (1968) traduzia esses princípios em uma legenda de aplicação mundial com 570 símbolos diferentes apresentada em cinco idiomas (inglês, russo, francês, alemão e polonês) (BASHENINA et al, 1968).

Com essa publicação a Subcomissão de Cartografia Geomorfológica completava grande parte do programa proposto durante o Congresso da UGI em Estocolmo (1960) e sua demissão era esperada ainda que restassem questões a resolver e projetos novos a realizar. Entretanto, a UGI mudou seu status para Comissão de Cartografia Geomorfológica, que deveria se responsabilizar pela organização do Manual de Cartografia Geomorfológica Detalhada.

A Comissão organizou o Manual, constituído por artigos da autoria de 20 geomorfólogos que contribuíram com informações sobre cartografia e cartas geomorfológicas e também sobre os atributos morfográficos, morfométricos, geológicos e outros mapas temáticos relativos a diferentes componentes do ambiente geográfico. Vários autores agregaram conhecimentos sobre métodos e técnicas de sedimentologia e análise de solos para acrescentar dados úteis à compartimentação geomorfológica, enquanto outros sistematizaram informações sobre o uso adequado dos mapas geomorfológicos para fins práticos. Outros capítulos incluem informações genéricas apropriadas para manuais básicos de visão restrita e conteúdo superficial, como no caso do capítulo sobre "cartografia geomorfológica em áreas de estruturas e climas variados" - onde se encontra a seção relativa às "regiões quentes e úmidas" - onde as informações sobre as estruturas do embasamento estão praticamente ausentes e predominam generalizações estreitas num total de 60 páginas onde as informações estruturais estão praticamente ausentes. 


\section{Considerações finais}

Este texto resume leituras, experiências e reflexões de e sobre publicações e resultados de pesquisas teóricas e de campo, individuais ou em equipe e em contextos variados, sobre cartografia geomorfológica, tanto básica quanto aplicada. A intenção inicial foi a de sintetizar e comentar os trabalhos apresentados na mesa redonda sobre tema homônimo e que integrou o programa do SINAGEO 2008. O tempo transcorrido desde esse evento possibilitou o amadurecimento do propósito original e, aos poucos, se desenvolveu esta síntese da fase inicial da cartografia geomorfológica de raiz europeia com vínculos geográficos e históricos com a geomorfologia climática, fundada no final dos anos 1920 em Düsseldorf e à qual se vincularam especialistas que participaram da fase inicial da cartografia geomorfológica detalhada.

\section{Referências bibliográficas}

BASHENINA, N. V.; GELLERT, J.; JOLY, J.; KLIMASZEWSKI, M,; SCHOLZ, E.; GILEWSKA, S. Project of the unified key to the detailed geomorphological map of the world. Folia Geographica, ser. Geogr. phys. II, 1- $40+$ List of landforms and signs for the detailed geomorphological map of the world. 1968.

BOESCH, H. Morphologische Karten. Schweizer Geograph., n. 22 , p. $56-65,1945$.

CENTRE NATIONAL DE LA RECHERCHE SCIENTIFIQUE. Leyenda para el mapa geomorfológico de Francia (1:50 000).Trad. e adapt. D. Serrat. Barcelona: CSIC. p. I -VI, 1 63, 1976.

DEMEK, J.; EMBLETON, C.; GELLERT, J.; VERSTAPPEN, H. eds. Manual of detailed geomorphological mapping. Czech. Ac. Sc. Praha. p. 1-344, 1972.

FAIRBRIDGE, R. W. (ed.). International organizations for geomorphology. In: The Encyclopedia of Geomorphology. New York: Reinhold, p. 560-563, 1968.

- (ed.) The encyclopedia of geomorphology. New

York: Reinhold, 1295 p., 1968.

GEHNE, H. Geomorphologische Karte der Umgebung von Thale, nach einer neuen Methode auf Grund eigener Beobachtungen dargesttellt. Mitt. Sächs. Thür. Ver. Erdkunde, v. 36, p. 1-8. 1912.

GELLERT, J. F. Preface - 1.The nature and aims of detailed geomorphological mapping. In: DEMEK, J.; EMBLETON, C.; GELLERT, J.; VERSTAPPEN, H. eds. Manual of detailed geomorphological mapping. Czech. Ac. Sc. Praha. p. 13-17, 1972.

HAYDEN, R. S. Geomorphological mapping. In: SHORT, N. M.; BLAIR, Jr., (eds.) Geomorphology from space: a global overview of regional landscapes. NASA, Scientific and Technical Information Branch. Washington, D.C, p. 637-656, 1989.

JOLY, F. VII.- Contribution française à la cartographie géomorphologique et à la connaissance cartographique du Quaternaire, IX Congrès International de I' INQUA: Le Quaternaire - Géodynamique, Stratigraphie et Environnement. CNFI, Paris, p. 231-232, 1973.

KLIMASZEWSKI, M. Morphology of the head of the White Water valley in the Tatra Mountains. Ochrona Przyrody n.19/ with geomophological map 1:50 000, 1950.

-------------- The principles of the geomorphological survey of Poland. In: CONGRÈS INTERNATIONAL DE
GÉOGRAPHIE, 18, Rio de Janeiro. Comptes Rendus. Rio de Janeiro. UGI - Comité National du Brésil, v. 2, p. 48-55, 1959. - The problem of the geomorphological field mapping of Poland. Przeglad Geogr. v. 25, p. 16-32, 1953.

Geomorphological Mapping, Poland, 3-12 May, 1962. Z. Geomorph. N. F., v. 6, n. 3/4, p. 357-359, 1962.

------- a Introduction to the discussion. Geographical Studies. Problems of Geomorphological Mapping, v. 46, p. 127-128, 1963.

- b Report of the International Conference of the Subcommission on Geomorphological Mapping. Geographical Studies. Problems of Geomorphological Mapping. v. 46, p. 8-12, 1963.

mapping in Poland. Geographical Studies. Problems of Geomorphological Mapping. v. 46, p. 67 - 71, 1963.

Journal. n. 3, p. 265-271, 1982.

- Detailed geomorphological maps. ITC

On constructing detailed geomorphological maps. Z. Geomorph. N.F. v. 32, n. 4, p. 457-470, 1988.

KLIMASZEWSKI, M.; TRICART, J. Resolutions adopted at the Conference of the Subcommission on Geomorphological Mapping. Geographical Studies. Problems of Geomorphological Mapping. v.46, p.129-130, 1963.

MICHEL, P. Les cartes géomorphologiques levées dans les bassins du Sénégal et de la Gambie(Afrique Occidentale). Geographical Studies. Problems of Geomorphological Mapping. v. 46, p. 73-81, 1963.

PARON, P; SMITH, M. Working Group on Applied Geomorphological Mapping. Acesso em fevereiro de 2009. Disponível na internet: http://www.geomorph.org/wg/ wgagm. html

PASSARGE, S. Über dies Herausgabe eines physiologischen Atlas. - Vehr.18. Dt. Geogr. Tag Innsbruck. p. 236-247, 1912.

- Morphologischer Atlas. Lfg I: Morphologie des Messtischblattes Stadtremda. Mitt. Geogr. Ges. Hamburg, v. 28, 1914.

------- Morphologischer Atlas. Lfg II: Morphologie des Messtischblattes Saalfeld. Mitt. Geogr. Ges. Hamburg, v. 43, 1920.

POKORNY, J; TYCZYÑSKA, M. Method of evaluation of relief for land planning purposes (on example of the region of Kraków). Geographical Studies. Problems of Geomorphological Mapping. Warszawa. v. 46, p. 95-99, 1963.

ST.-ONGE, D. A. Geomorphological map legends, their problems and their value in optimum map utilization. Geographical Bulletin, v. 22, p. 5-12, 1964.

Geomorphic maps. In: FAIRBRIDGE, R. W. (ed.) The Encyclopedia of Geomorphology. New York: Reinhold. p. 388-403, 1968.

p. Canadian Geographer, v. 30, n., p. 307-315, 1981.

TRICART, J. Un complement des cartes géologiques - les cartes géomophologiques. Bull. Soc. Géol.France, v. 6, p. 739-750, 1954.

--Présentation d'une feuille de la carte gémorphologique du Delta du Sénégal au 1:50 000. Rev. Géom. Dyn, v. 10, n. 5-6 à 11-12, p. 106-116, carta anexa, 1959.

- Cartes géomorphologiques et géomorphologie appliquée. L' experience du Centre de Géographie Appliquée. Geographical Studies. Problems of Geomorphological Mapping. Warszawa, n. 46, p. 113-120, 1963. 